\title{
The Enlightenment of Italian Opera to the Development of Chinese Opera
}

\author{
Yue Pan, Huiling Jiang \\ Euro-Languages College, Zhejiang Yuexiu University of Foreign Languages, Shaoxing, China \\ Email: 576828479@qq.com
}

How to cite this paper: Pan, Y. and Jiang, H.L. (2021) The Enlightenment of Italian Opera to the Development of Chinese Opera. Open Access Library Journal, 8: e7593. https://doi.org/10.4236/oalib.1107593

Received: May 27, 2021

Accepted: June 22, 2021

Published: June 25, 2021

Copyright $\odot 2021$ by author(s) and Open Access Library Inc.

This work is licensed under the Creative Commons Attribution International License (CC BY 4.0).

http://creativecommons.org/licenses/by/4.0/

\begin{abstract}
In early 1920s, under the impact of the wave of Western culture, traditional Chinese music faced unprecedented difficulties. This article combines the development history and representative repertoire of Western operas represented by Italy and Chinese national operas, and puts forward insights on the development trend of Chinese national operas and how to better develop Chinese national operas in stages.
\end{abstract}

\section{Subject Areas}

Art

\section{Keywords}

Chinese National Opera, Italian Opera, Period, Development Trend

\section{1. 引言}

歌剧(Opera)是一种音乐表现形式, 是一门主要或完全以声乐和器乐教学 表现来交代剧情的舞台艺术, 采用了大量的咏叹调和宣叙调。歌剧大都用美 声唱法, 追求高难度的歌唱技巧和戏剧性的表现力, 对演唱者的唱功要求远 远高于流行歌曲。

\section{2. 意大利歌剧的发展}

歌剧最早滥解于 16 世纪的意大利。然而事实上, 直到 16 世纪末, 真正 的西洋歌剧才随着文艺复兴时期大行其道。

\section{1. 意大利歌剧的问世}

16 世纪末叶, 意大利佛罗伦萨的一群学者墨客—— “佛罗伦萨小厅集 
团” (Florentine Camerata)——在人文主义思想的鼓励和引导之下, 力求恢复 古希腊传统戏剧[1]。他们主张采用希腊悲剧中的演唱形式, 强调单音音乐的 表现力。1598 年, 音乐史上第一部歌剧——《达芙妮》(Dafne)在佛罗伦萨上 演并大获成功（遗憾的是其乐谱并没有保留下来）。此后, 佛罗伦萨歌剧逐 渐传播开来, 影响了其他区域, 最终形成 17 世纪欧洲四大乐派一一佛罗伦萨 乐派、威尼斯乐派、罗马乐派、那不勒斯乐派。

克劳迪奥 - 蒙特威尔地(Claudio Monteverdi, 1567-1643)作为前期巴罗克 乐派举足轻重的代表人物之一, 他的音乐宛若人的躯体, 富有鲜明的个性和 炽热的情感, 将巴洛克音乐推向高潮。创作于 1607 年的歌剧《奥菲欧》 (L'Orfeo), 是历史上最早期的一批歌剧之一, 影响了整个欧洲的音乐发展, 直到今天仍显示出巨大的震撼力 $[1]$ 。

\section{2. 意大利歌剧的发展}

然而, 日中则移, 月满则亏, 物盛则衰, 天之常数也。18 世纪后的正歌 剧, 随着欧洲启蒙运动的发展, 民主共和思想深入人心, 正歌剧之题材僵化, 创作形式故步自封, 创作内容脱离现实, 难以被大众所认可。加上阉伶 (castrato)在舞台上占据着支配和主导地位, 由于虚荣心作宗过分炫技和展示 自己, 破坏了歌剧的连贯性, 引起人们普遍的反感。

但正歌剧(opera seria)的没落与喜歌剧(opera buffa)的兴起, 并不是 “和平 过渡” 的。在改革派中, 德国作曲家格鲁克(Gluck 1714-1787)是不可或缺的一 位。他认为歌剧应优美而简洁。他遵循一切艺术品都应回归质朴、真实的原 则, 认为音乐与戏剧的发展不可分割, 从而增强音乐的表现力。为落实这一 主张, 格鲁克创作了《奥菲欧与尤里狄茜》(Orfeo ed Euridice), 取材于希腊 神话奥菲奥。却在形式上做了很大改动。当时社会腐化的歌剧艺术经格鲁克 改革后宛若新生, 深刻影响了后世歌剧及其理论的发展。

\section{3. 意大利歌剧的繁荣}

18 世纪末, 意大利歌剧日渐式微, 直至 19 世纪初以意大利歌剧三杰-一 罗西尼(Gioacchino Rossini, 1792-1868)、威尔第(Giuseppe Verdi, 1813-1901)和 普契尼 (Giacomo Puccini, 1858-1942)为代表的作曲家重新树起传统歌剧的㫌 旗, 这才恢复了它在欧洲的重要地位。

罗西尼生于意大利民族运动兴起的年代, 为他生活和创作留下了深刻的 印记。他将喜歌剧与正歌剧糅合在一起, 这焕然一新的改革对后世歌剧创作 产生了重大的影响。主要歌剧作品有《塞维利亚理发师》、《奥塞罗》等。

威尔第通过研磨前人的作品和长期自我探索, 逐渐形成了独特的创作风 格, 扬名意大利, 将意大利歌剧推向巅峰。他本着对艺术敬畏、对观众负责 的态度, 抵制虚无的形式主义, 强调表演应面向观众, 让观众沉浸于音乐之 中。加之威尔第对外国影响的刻意回避, 从而赢得了 “意大利革命音乐大师” 的称呼。主要作品有: 《弄臣》、《茶花女》等。

普契尼是 “现实主义” 歌剧音乐流派的代表人物, 他取材于日常生活, 
创作追求紧张戏剧情感, 以简单的故事反映下层普通人民的悲剧, 揭开社会 的阴暗面, 受到广泛好评和热烈拥护。代表作有《波西米亚》和《蝴蝶夫人》。

\section{3. 中国歌剧的发展}

中国歌剧于 20 世纪 20 年代诞生, 距今已有近百年的历史。受 “西学东 渐” 和 “五四运动” 的影响, 一些有识之士不断吸收和借鉴西方歌剧理论, 并结合中国独特的民族风格, 走过坎坎坷坷, 经历风风雨雨, 最终形成了具 有中国特色的歌剧艺术一一新歌剧。

\subsection{0 世纪 20 年代时期}

1919 年的五四运动是一次伟大的思想解放运动, 涉及中国政治经济文化 等多方面。除此之外, 还为了帝国主义的侵略, 中国的一些有识之士开始学 习、借鉴西方艺术形式并结合中国独特的民族文化 [2]。中国民族歌剧就是在 这种背景之下产生的。代表曲目有《麻雀与小孩》、《军民大生产吧》等。

但由于过度的西洋化, 而在音乐的民族化、大众化方面有所欠缺, 新歌 剧并不能迎合国人的品味, 没有为中国观众所接受和喜爱。

\section{2. 新中国成立前后}

1942 年在延安举行了文艺座谈会, 与此同时, 延安的共产党人还发动了 延安整风和群众生产运动, 大大激发了文艺工作者的创作热情, 中国歌剧《白 毛女》应运而生。它把强烈的浪漫主义情怀和共产党的阶级斗争理论汇集起 来, 深刻反映当时的社会问题, 因此倍受国民欢迎。《白毛女》是中国新民 族歌剧的基石。形成了自身鲜明的美学品格, 中国新歌剧的正式起点就由此 开始[2]。

1964 年, 《江姐》经中国社会人民共和国解放军空军政治部文工团改编 登上世界歌剧舞台。相较于其原型小说, 歌剧《江姐》在脚本和音乐创作上 不仅吸收了西洋歌剧的手法, 还更多的融入了较强的民族元素, 增添了更为 强烈的戏剧性和鲜明的民族风格。凭借其生动形象的表现手法、广泛的受众 群体, 成为继《白毛女》之后中国歌剧发展的又一高峰[3]。

中华人民共和国成立之后, 进一步在歌剧事业中上下求索、锐意进取, 成就了《刘胡兰》、《赤叶河》等优秀剧作。

\section{3. 十年文革后}

1966 1976 年发动的文化大革命对教育、科学、文化的破坏尤其严重, 中国歌剧事业几乎处于停滞甚至倒退的状态。这一萧条的景象直到改革开放 后人们思想逐渐解放, 中国歌剧才逐渐复苏, 迎来了百花齐放的春天。

改革开放后, 歌剧创作进入亘古未有的井喷期, 题材范围也比以往拓宽 了不少, 体裁风格向多样化发展, 所反映的社会现象更为深刻, 人物形象也 更为立体饱满。在此期间, 许多形式新颖、内容丰富的剧集, 如《星光啊星 光》、《第一百个新娘》、《伤逝》等, 如雨后春笋般不断涌现。 


\section{4. 新时期}

进入 21 世纪, 我国歌剧也随之步入了一个新时期。随着国外优秀剧目的 引进、国内专业人才的培养和观众鉴赏水平的提高, 我国歌剧经过数十年的 艰苦探索, 走过了千山万水, 逐渐找到了属于自己的位置, 迎来了自己的丰 收之年[4]。特别是自 2007 年国家大剧院开业以后, 不断推出《长征》、《冰 山上的来客》、《我的母亲叫太行》等经典原创歌剧。

\section{4. 中国歌剧现存的问题及意大利歌剧对中国歌剧的启示}

然而尽管中国歌剧如今乘风破浪、屡创佳绩, 却由于种种原因导致其在 人民群众之中的影响还远不如建国后五、六十年代的歌剧创作, 因此, 要真 正在国际歌剧舞台上占有一席之地还存在一定难度。

\section{1. 中国歌剧现存问题}

近年来, 中国歌剧处于困顿时期, 不仅是受快餐文化盛行的影响, 人们 追求速成, 耐不下心来走进剧院; 更多的得从自身找原因。

\subsection{1. 缺乏优秀原创剧本}

尽管近年来中国歌剧市场蒸蒸日上, 其中却有不少观众为了追星花大价 钱进剧院，对由虚假宣传、成本飞涨、炫耀性消费所导致的天价票视若无睹 (2010 年广州大剧院开幕上演的歌剧《图兰朵》, 一张最贵的票高达 2880 人 民币), 这种虚假繁荣的表象背后是中国歌剧产业缺乏高质量的原创剧本事 实。这一判断来自原创歌剧投入市场后没有得到很好反馈, 除了市场运作等 客观因素外, 剧本是一个重要原因。为解决这个燃眉之急, 我们必须用以中 国文化为内核的作品赢得国民的支持, 将来才可能进入国际市场。但多数歌 剧院在推出所谓中国原创歌剧时却忽视了这一点, 也因此缺乏受众群体 [5]。

\subsection{2. 专业型人才不足}

我国歌剧行业专业型人才的不足, 制约了我国创作出经典作品的可能性, 因而必须加大技能人才教育培养的力度。只有足够专业的制作人员才能在歌 剧创作中发现问题, 提出问题, 并解决问题。从而进一步促进我国歌剧事业 的发展。目前来说, 我国的歌剧演员们的表演水平已达到西方水平, 但是这 些优秀演员的数量依然远远不足以满足趋于成熟的市场 [5]。

\subsection{3. 专业型剧场短缺}

在国内歌剧剧院数量分布不均, 且设施完备的剧院微乎其微, 一些落后 地区甚至连基础的条件都难以满足。加之国家对歌剧产业支持力度的不够, 这些原因或多或少都造成歌剧在中国成为小众文化。换言之, 中国缺少的不 是歌剧演员, 而是能够展现其表演才华, 并在实践中不断提高其表演技能的 舞台。

\section{2. 意大利歌剧对中国歌剧发展的启示}

作为文艺复兴的发源地, 意大利在文化上开放的态度使它形成了一种全 
民化追求知识的文化氛围, 尤其热衷于古希腊罗马文化。可以说, 文艺复兴 运动促进了歌剧体裁的诞生。以克劳迪奥 - 蒙特维第为代表, 他将文艺复兴 时期与巴洛克时期风格联系起来, 创作出了首部戏剧性歌剧《奥菲欧》, 一 经问世即大获成功, 赢得当地人民的肯定与喜爱。

到了启蒙运动时期, 新思维不断涌现并孕育和推动了资本主义的形成。 同时, 传统意大利歌剧在发展过程中不再注重体现音乐要表达的思想, 逐渐 走上极端, 引起观众的不满。由此引发了以格鲁克为代表的一些艺术家对正 歌剧的改革, 并于 18 世纪 70 年代创作了《奥菲欧与尤里狄茜》等歌剧, 不 仅使意大利歌剧转危为安, 其美学观点也启发了后世许多著名歌剧作曲家的 思考和探索。

参考上述两段意大利歌剧发展过程中所经历的起伏, 我们可以得出, 艺 术源于生活。社会变革影响了歌剧的发展与传播, 为音乐家思想观念、审美 意识、艺术风格的形成及其音乐活动提供了一定的外部条件。这一点, 也同 样适用于中国。

然而, 意大利歌剧所形成与体现的风格特色反映的是意大利人日常社会 生活, 与意大利文化密不可分。中国歌剧也应该包括对民族文化的剖析, 切 不可照搬, 因为中国歌剧不是西方歌剧的翻版, 我们不应该仅仅追求其外在 表演形式的相似, 而应该向内探索, 寻求其内核体现中国精神, 内容立足中 国国情, 从本土文化出发, 达到与大众审美相吻合又能引领大众审美向更高 水平发展的情形。

回顾中国歌剧发展历史, 完美诠释了这一点并最具影响力的莫过于《扬 子江暴风雨》。该剧以上海 “一・二八” 事变之后, 码头工人在中国共产党 的领导下反抗日寇和国民党反动统治而举行大罢工, 这一真实事件为背景, 是我国第一部反映工人阶级的歌剧, 也是我国歌剧史上浓墨重彩的一笔。《扬 子江风暴》以码头为舞台, 描写老百姓艰苦卓绝的生活和他们反抗的对象。 虽然唱功技法与意大利歌剧相比略显稚嫩, 但其质朴的旋律、锃铭的节奏, 使布满靡靡之音的上海有如醍醐灌顶, 一时激荡人心。连演数场, 场场爆满。 除此之外, 更有《白毛女》、《原野》等经典剧目的不断涌现。

反观当下, 部分歌剧题材抱残守缺, 因不能反映时代发展而失去了大量 受众群体, 这不恰恰说明了中国故事和中国情感在歌剧中重要性吗? 中国歌 剧的每一步都要体现时代精神, 都应面向观众, 真正形成以观众为核心的表 演体裁。这一时期的中国歌剧可以参考意大利歌剧发展史中格鲁克对其进行 的改革, 他汲取百家之长, 救歌剧于水火之中。中国需要这样的 “格鲁克们” 来进行各种实验和革新: 十字路口, 他们没有彷得和失落, 因为前方的灯塔 早已照亮远方。

鲁迅对于先生曾说: 越是一个民族的, 就越是成为世界的。只有走符合 中国国情的道路, 才能找到独属于自己的艺术魅力, 在世界舞台上闪耀。

\section{3. 中国歌剧实现本土化并在其基础上走向世界}

中国歌剧应一切以观众为尺度: 凡是观众可以理解的地方, 就可以保留; 凡是观众不能理解的地方, 有必要替换。周恩来总理也曾说 “少数洋的东西 
可以保持, 但是多数是要能在中国土壤里植根成长的” 。作为中国歌剧, 就 必然需要讲述中国故事、选择适合中国现代生活的题材以打动中国观众。

意大利歌剧发展至今已经形成了一套独特的审美体系。对此, 我们不仅 要持开放包容的态度, 还需要强调理论自信, 着重表现中国艺术独有的审美 追求, 立足于中国文化特色社会主义道路。中国之美, 美在意象, 通过虚实 结合, 情景交融等手法营造意境美, 从而给观众带来独具一格的体验, 是中 华文化精华之所在。

“只有民族的才是世界的”。理性选择, 择善而从。传统戏剧、民俗器 乐是我国特有的, 我们要在创作中考虑到如何将歌剧这种外来形式与之相融 合，广泛借鉴我国民间艺术的表现形式，坚持立足本国、辩证结合从而使我 们的歌剧更贴近中国观众, 并让全球热爱歌剧的人们领略不一样的中国美。

中国歌剧发展至今经历了探索、黑暗、蜕变, 尽管不是一帆风顺, 但不 同于那遥不可及的星, 通过不断的创作尝试和不解的人才培养, 必将乘风破 浪。为此, 应努力开拓创新, 推动中国特色的歌剧艺术更加繁荣发展, 相信 在时光的淬炼下, 心怀热忱, 坚持自我, 全情投入, 终能走向世界, 走向未 来。

\section{Conflicts of Interest}

The authors declare no conflicts of interest regarding the publication of this paper.

\section{References}

[1] 张羽. 浅谈意大利歌剧的产生与发展 [J]. 社科纵横, 2007, 22(2): 110-113.

[2] 万和荣. 中国民族歌剧产生的历史成因 [J]. 艺术百家, 2007(2): 174-177.

[3] 杨曙光, 金永哲. 中国歌剧演唱研究[J]. 中国音乐, 2010(2): 168-177.

[4] 秦春风. 简析中国民族歌剧不同时期的发展状况 [J]. 北方音乐, 2011(11): 63 .

[5] 郭建民. 关于中国歌剧的生存与发展问题[J]. 乐府新声, 2002(3): 42-45.

\section{Appendix (Abstract and Keywords in Chinese)}

\section{意大利歌剧对中国歌剧发展的启示}

摘要: 20 世纪初, 在西洋文化浪潮的冲击下, 中国传统音乐面临前所未 有的困境。文章结合以意大利为代表的西洋歌剧以及中国民族歌剧的发展历 史及代表曲目，分阶段的就中国民族歌剧发展趋势并如何更好的发展中国民 族歌剧提出见解。

关键词: 中国民族歌剧, 意大利歌剧, 时期, 发展趋势 